\title{
Evolution of insulin sensitivity and its variability in out-of-hospital cardiac arrest (OHCA) patients treated with hypothermia
}

Azurahisham Sah Pri ${ }^{1}$, J Geoffrey Chase ${ }^{1}$, Christopher G Pretty ${ }^{1 *}$, Geoffrey M Shaw ${ }^{2}$, Jean-Charles Preiser ${ }^{3}$, Jean-Louis Vincent ${ }^{3}$, Mauro Oddo ${ }^{4}$, Fabio S Taccone ${ }^{3}$, Sophie Penning ${ }^{5}$ and Thomas Desaive ${ }^{5}$

\begin{abstract}
Introduction: Therapeutic hypothermia (TH) is often used to treat out-of-hospital cardiac arrest (OHCA) patients who also often simultaneously receive insulin for stress-induced hyperglycaemia. However, the impact of TH on systemic metabolism and insulin resistance in critical illness is unknown. This study analyses the impact of TH on metabolism, including the evolution of insulin sensitivity $\left(S_{1}\right)$ and its variability, in patients with coma after OHCA.

Methods: This study uses a clinically validated, model-based measure of $S_{\text {. }}$. Insulin sensitivity was identified hourly using retrospective data from 200 post-cardiac arrest patients (8,522 hours) treated with TH, shortly after admission to the intensive care unit (ICU). Blood glucose and body temperature readings were taken every one to two hours. Data were divided into three periods: 1) $\left.\mathrm{cool}\left(\mathrm{T}<35^{\circ} \mathrm{C}\right) ; 2\right)$ an idle period of two hours as normothermia was re-established; and 3) warm $\left(T>37^{\circ} \mathrm{C}\right)$. A maximum of 24 hours each for the cool and warm periods was considered. The impact of each condition on $\mathrm{S}_{1}$ is analysed per cohort and per patient for both level and hour-to-hour variability, between periods and in six-hour blocks.
\end{abstract}

Results: Cohort and per-patient median S, levels increase consistently by $35 \%$ to $70 \%$ and $26 \%$ to $59 \%(P<0.001)$

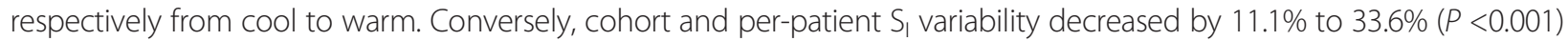
for the first 12 hours of treatment. However, S, variability increases between the 18th and 30th hours over the cool to warm transition, before continuing to decrease afterward.

Conclusions: OCHA patients treated with TH have significantly lower and more variable $\mathrm{S}_{\text {, }}$ during the cool period, compared to the later warm period. As treatment continues, S, level rises, and variability decreases consistently except for a large, significant increase during the cool to warm transition. These results demonstrate increased resistance to insulin during mild induced hypothermia. Our study might have important implications for glycaemic control during targeted temperature management.

\section{Introduction}

Hyperglycaemia is prevalent in critical care [1-4] and increases the risks of further complications and mortality $[1,4,5]$. Glycaemic control has shown benefits in reducing mortality and morbidity $[4,6,7]$. However, many studies have found it difficult to reproduce these results [8-10] due in part to metabolic variability [11]. Out-of-hospital cardiac arrest (OHCA) patients often experience hyperglycaemia $[12,13]$. These patients belong to one group who

\footnotetext{
* Correspondence: chris.pretty@canterbury.ac.nz

${ }^{1}$ Centre for Bio-Engineering, Department of Mechanical Engineering, University of Canterbury, 20 Kirkwood Avenue, Christchurch 8140, New Zealand

Full list of author information is available at the end of the article
}

can be highly insulin resistant and variable, particularly on the first two days of stay [14], as well as those who may particularly benefit from glycaemic control [4].

Therapeutic hypothermia $(\mathrm{TH})$ is often used with OHCA patients to protect against brain injury $[15,16]$, which leads to a lowering of metabolic rate, reduces plasma insulin, induces insulin resistance and alters blood glucose homeostasis [17]. One of the adverse events associated with hypothermic therapy is a decrease in insulin sensitivity and endogenous insulin secretion [18]. However, this decrease may not be observable in a cohort who is already highly insulin resistant and variable [14]. Hence, understanding metabolic evolution and variability would enable 
safer and more accurate glycaemic control using insulin in this cohort. This study analyses the evolution of a clinically validated model-based measure of insulin sensitivity $\left(\mathrm{S}_{\mathrm{I}}\right)$ in OHCA patients to assess the impact of hypothermia therapy.

\section{Methods}

\section{Patients and data}

A retrospective analysis of glycaemic control data from 200 OHCA patients (8,522 hours) treated with $\mathrm{TH}$, shortly after admission to intensive care. Data was obtained from intensive care units (ICUs) at Christchurch Hospital, New Zealand, at Erasme Hospital, Belgium, and CHUV-Lausanne Hospital, Switzerland. Patients from Christchurch Hospital $(\mathrm{N}=20)$ were on the specialized relative insulin and nutrition titration (SPRINT) glycaemic control protocol [7], whereas the remaining 180 patients from Erasme $(\mathrm{N}=99)$ and Lausanne $(\mathrm{N}=81)$ hospitals were on local glycaemic control protocols and included in an institutional database (2008 to 2012).

Blood glucose (BG) and temperature readings were taken one to two hourly. Data were divided into three periods: 1$)$ cool $\left(\mathrm{T}<35^{\circ} \mathrm{C}\right)$; 2$)$ an idle period of two hours as normothermia was restored; and 3$)$ warm $\left(\mathrm{T}>37^{\circ} \mathrm{C}\right)$. A maximum of 24 contiguous hours and a minimum of 15 hours for each period were considered, ensuring a balance of contiguous data between periods. Overall demographics are shown in Table 1.

Glycaemic targets while treating OHCA patients in the three units were very similar and overlapped. The SPRINT protocol, used in the Christchurch Hospital ICU, targeted 4.0 to $7.0 \mathrm{mmol} / \mathrm{L}$ [7]. The protocol used in both the Erasme and Lausanne ICUs differed from SPRINT, but targeted 6.0 to $8.0 \mathrm{mmol} / \mathrm{L}$ [17]. Although two different protocols were used in the three units, the targets were very similar and within the relatively tight 4.0 to $8.0 \mathrm{mmol} / \mathrm{L}$ range.

Table 1 Demographic data and treatment information for both the cool and warm periods

\begin{tabular}{lll}
\hline Variables & Value & \\
\cline { 2 - 3 } & Cool & Warm \\
\hline Total patients, number (n) & 200 & \\
Median age, years & $61[51,72]$ & \\
Female gender, number (\%) & $40(20.6 \%)$ & \\
ICU mortality, number (\%) & $85(45.6 \%)$ & \\
Diabetes status, number (\%) & $26(13.0 \%)$ & \\
Total treatment, hours (h) & 4219 & 4303 \\
Blood glucose, median (mmol/L) & $7.6[6.3,9.7]$ & $6.8[5.9,8.0]$ \\
Insulin rate, median (U/hr) & $3.4[1.3,8.0]$ & $3.5[1.6,7.0]$ \\
Glucose rate, median (g/hr) & $2.7[1.0,5.3]$ & $5.4[2.7,8.1]$ \\
\hline
\end{tabular}

IQR: [interquartile range].
Audit of the clinical data from SPRINT was given by the Upper South B Regional Ethics Committee and for the data study by Taccone et al. [17]. No approval was required as it was also a retrospective audit.

\section{Model-based insulin sensitivity}

Model-based $S_{I}$ in this study is a patient-specific parameter describing the overall whole-body effect of insulin. $S_{\text {I }}$ is identified for each hour, for each patient using a clinically validated glucose-insulin model [19-23]. The key model equations are defined:

$$
\begin{aligned}
\dot{G}= & -p_{G} \cdot G(t)-S_{I}(t) \cdot G(t) \cdot \frac{Q(t)}{1+\alpha_{G} Q(t)}+\frac{P(t)+E G P-C N S}{V_{G}} \\
\dot{I}= & -n_{K} I(t)-\frac{n_{L} I(t)}{1+\alpha_{I} I(t)}-n_{I}(I(t)-Q(t))+\frac{u_{e x}(t)}{V_{I}} \\
& +\left(1-X_{L}\right) \frac{u_{e n}(t)}{V_{I}} \\
\dot{Q}= & n_{I}(I(t)-Q(t))-n_{C} \frac{Q(t)}{1+\alpha_{G} Q(t)}
\end{aligned}
$$

Where $G(t)$ represents the concentration of blood glucose $(\mathrm{mmol} / \mathrm{L}) . I(t)$ and $Q(t)$ represent the plasma insulin and insulin interstitial concentrations $(\mathrm{mU} / \mathrm{L})$ respectively. Model parameters, rates and constants in this model were as fully defined in $[21,24]$.

Model-based $\mathrm{S}_{\mathrm{I}}$ is identified hourly from patient data, producing an hourly piece-wise constant profile [25], capturing the whole-body glycaemic response to exogenous insulin and nutrition. The validity and independence of this patient-specific parameter have been validated using data from independent, clinically matched cohorts [19], in comparison to gold-standard insulin sensitivity tests [22] and in clinical glycaemic control $[20,23]$.

\section{Analyses and metrics}

$\mathrm{S}_{\mathrm{I}}$ level and variability during the cool $\left(\mathrm{T} \leq 35^{\circ} \mathrm{C}\right)$ and warm $\left(\mathrm{T}>35^{\circ} \mathrm{C}\right)$ periods are analysed on per-cohort and per-patient bases using six-hour blocks of data as per Table 2. $\mathrm{S}_{\mathrm{I}}$ level is compared between blocks as a cohort median and by per-patient median $\mathrm{S}_{\mathrm{I}}$. Similarly, $\mathrm{S}_{\mathrm{I}}$ variability is calculated as the hour-to-hour percentage change in $\mathrm{S}_{\mathrm{I}}\left(\Delta \% \mathrm{~S}_{\mathrm{I}}\right)$ and is analysed per cohort for each block.

$$
\% \Delta \mathrm{SI}=\frac{\left(S_{I_{n+1}}-S_{I_{n}}\right)}{S_{I_{n}}} \times 100
$$

The use of percentage change, rather than absolute change, normalises the metric so patients with differing $\mathrm{S}_{\mathrm{I}}$ levels can be compared fairly. 
Table 2 Descriptions of six-hour blocks for data analysis

\begin{tabular}{|c|c|c|c|c|}
\hline Day & Period & Analysis & Block & Hour range \\
\hline \multirow[t]{4}{*}{1} & Cool & 6-hour block & 1 & $0-6$ hours \\
\hline & & & 2 & $6-12$ hours \\
\hline & & & 3 & $12-18$ hours \\
\hline & & & 4 & $18-24$ hours \\
\hline
\end{tabular}

Idle 2-hour period in between cool and warm

\begin{tabular}{lll}
2 6arm & 5 & $24-30$ hours \\
& 6 & $30-36$ hours \\
& 7 & $36-42$ hours \\
& 8 & $42-48$ hours \\
\hline
\end{tabular}

Bagshaw et al. [26] reported an association between both hypoglycaemia and BG variability with mortality during the first 24 hours of ICU stay. Thus, the acute evolution of $\mathrm{S}_{\mathrm{I}}$ over the first day using six-hour blocks was analysed as $S_{I}$ variability is a key contributor to BG variability. For the cohort analysis, $\mathrm{S}_{\mathrm{I}}$ and $\Delta \% \mathrm{~S}_{\text {I }}$ data from all patients was grouped into each appropriate time block. Median values for each time block were calculated for comparison to the previous block, thus capturing overall cohort changes over time in level and hourto-hour variability.

For the per-patient analysis, the median value of $\mathrm{S}_{\mathrm{I}}$ and the interquartile range (IQR) of $\Delta \% \mathrm{~S}_{\mathrm{I}}$ were calculated for each patient, for each time block. The IQR captures the width or degree of variability for a given patient within each six-hour block. Thus, a reduction in the IQR of $\Delta \%$ $\mathrm{S}_{\mathrm{I}}$ over time would indicate a reduction in hour-to-hour variability for a given patient.

$\mathrm{S}_{\mathrm{I}}$ level and variability are non-Gaussian and thus compared using non-parametric statistics and cumulative distribution functions (CDFs). CDFs are particularly useful as they show the entire distribution that is often summarised as a median and IQR. The CDF for a given value of the independent variable (for example $S_{I}=x$ ) describes the probability of observing a value less than or equal to $\mathrm{x}$. All distributed data were compared using a Wilcoxon ranksum test (Mann-Whitney $U$ test), except for $S_{I}$ variability results. $S_{I}$ variability was compared using the KolmogorovSmirnov (KS) test as it has greater power to detect differences in the shape of distributions when median values are similar. In all cases, $P<0.05$ is considered statistically significant.

\section{Results}

\section{$\mathrm{S}_{\mathrm{I}}$ level analyses}

Figures 1 and 2 present the CDFs of hourly $S_{I}$ level by cohort and median $S_{I}$ per patient, respectively, using six-hour blocks. Table 3 presents the increase in median insulin sensitivity and corresponding $P$ values between successive time blocks.

The results suggest that $S_{I}$ increases for the cohort and per patient are statistically significant for the first 36 hours $(P<0.05)$ in both cases.

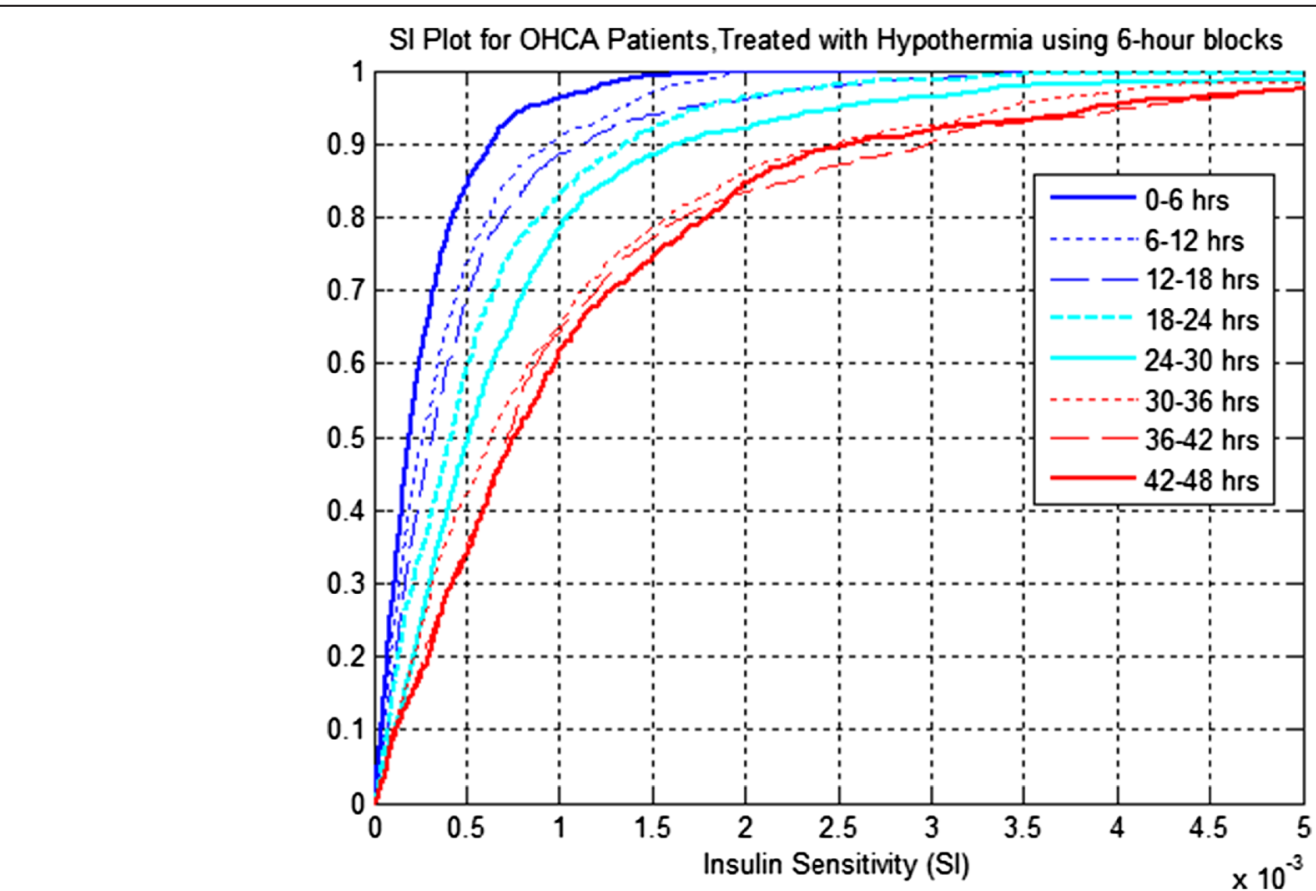

Figure 1 Insulin sensitivity $\left(\mathrm{S}_{1}\right)$ level distribution per cohort for out-of-hospital cardiac arrest $(\mathrm{OHCA})$ patients, treated with therapeutic hypothermia (TH) using six-hour blocks for both cool and warm periods. 


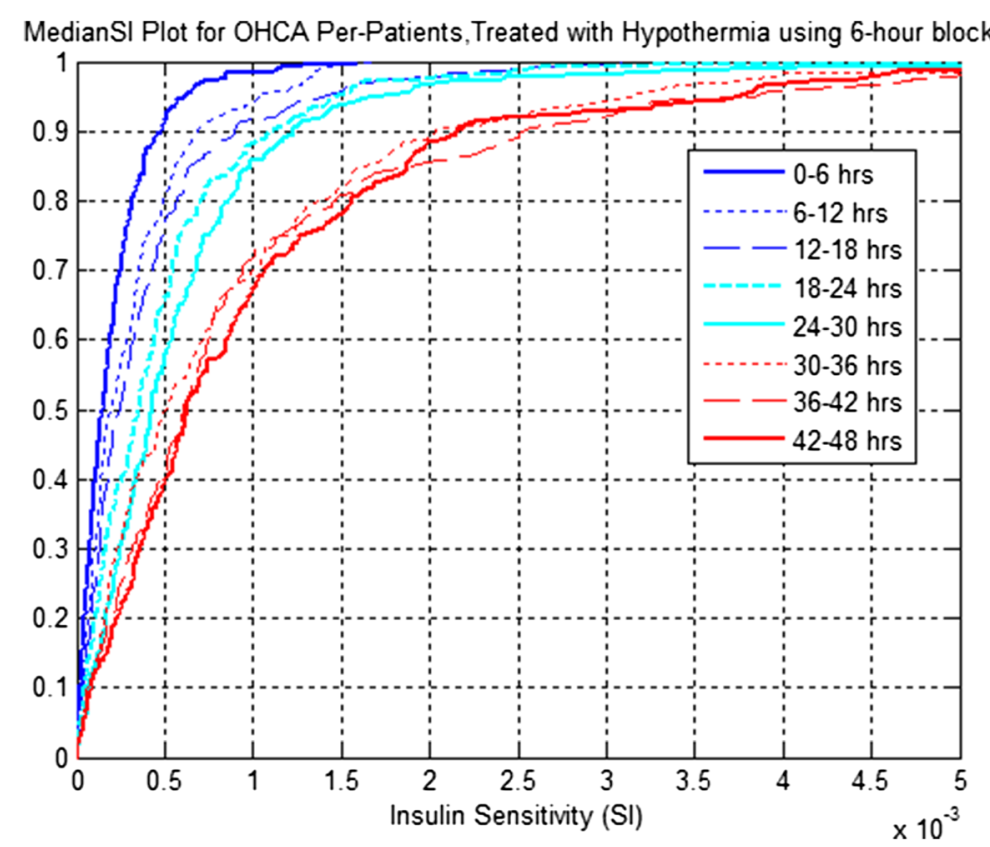

Figure 2 Insulin sensitivity $\left(\mathrm{S}_{\mathrm{I}}\right)$ level distribution per patient for out-of-hospital cardiac arrest (OHCA) patients, treated with therapeutic hypothermia (TH) using six-hour blocks for both cool and warm periods.

Table 3 Increasing cohort and per-patient median $S_{1}$ during cool and warm periods as per six-hour blocks of data, where the $P$ values compare successive six-hour blocks as shown in the first column for both the overall cohort and per-patient median values

\begin{tabular}{|c|c|c|c|c|}
\hline \multirow{2}{*}{$\begin{array}{l}\text { SI level } \\
\text { analysis } \\
\text { (6-hr blocks) }\end{array}$} & \multicolumn{2}{|c|}{ Cohort analysis } & \multicolumn{2}{|c|}{ Per-patient analysis } \\
\hline & $\begin{array}{l}\text { \% } S_{1} \text { median } \\
\text { increase }\end{array}$ & $P$ value & $\begin{array}{l}\% S_{1} \text { median } \\
\text { increase }\end{array}$ & $P$ value \\
\hline Block 1-2 (C) & 35.1 & $<0.05$ & 26.4 & $<0.05$ \\
\hline \multicolumn{5}{|l|}{ (0-6 vs. 6-12 hr) } \\
\hline Block 2-3 (C) & 19.2 & $<0.05$ & 31.1 & $<0.05$ \\
\hline \multicolumn{5}{|l|}{ (6-12 vs. $12-18 \mathrm{hr}$ ) } \\
\hline Block 3-4 (C) & 31.8 & $<0.05$ & 42.4 & $<0.05$ \\
\hline \multicolumn{5}{|l|}{ (12-18 vs. $18-24$ hr) } \\
\hline Block 4-5 (C-W) & 23.4 & $<0.05$ & 18.3 & $<0.05$ \\
\hline \multicolumn{5}{|l|}{ (18-24 vs. $24-30$ hr) } \\
\hline Block 5-6 (W) & 23.9 & $<0.05$ & 23.2 & $<0.05$ \\
\hline \multicolumn{5}{|l|}{ (24-30 vs. $30-36$ hr) } \\
\hline Block 6-7 (W) & 13.1 & 0.06 & 15.8 & 0.2 \\
\hline \multicolumn{5}{|l|}{ (30-36 vs. $36-42$ hr) } \\
\hline Block 7-8 (W) & 4.4 & 0.4 & 3.2 & 0.5 \\
\hline (36-42 vs. $42-48$ hr) & & & & \\
\hline
\end{tabular}

$P$ values are calculated using Wilcoxon rank-sum test. $\mathrm{S}_{\mathrm{l}}$, insulin sensitivity metric (model-based).
Results in Figure 2, Figure 3 and Table 3 are further reflected in Table 4, which shows that $S_{\text {I }}$ increases for a large proportion of patients between the six-hour blocks over the first 36 hours of ICU stay. Table 4 also shows that after 48 hours of treatment, only $86 \%$ of patients show rise in $S_{I}$ from the first six hours. Thus, while the general trend is obvious for increasing $\mathrm{S}_{\mathrm{I}}$, it is not guaranteed for all patients. Equally, these increases decelerate in terms of number of patients with increasing $S_{I}$ over time, going from left to right in the table.

\section{$S_{1}$ variability analyses}

Figures 3 and 4 present the CDFs for changes in $S_{\text {I }}$ $\left(\% \Delta S_{I}\right)$ for six-hourly blocks per cohort and $50 \%$ range of $S_{I}$ variability per patient, respectively. Table 5 presents the reductions between successive blocks.

Cohort and per-patient variability decreases for the first 24 hours. However, it increases across the cool to warm transition, indicating some potential stress across the cool to warm transition with negative reductions. The decreasing trend returns for all subsequent blocks. The results suggest that $\% \Delta \mathrm{S}_{\text {I }}$ decreases per cohort and per patient are statistically significant $(P<0.05)$ for the first 36 hours in both cases.

\section{Discussion}

Insulin sensitivity level

The $S_{I}$ level results for both per-cohort and per-patient analysis suggest that $\mathrm{OHCA}$ patients undergoing $\mathrm{TH}$ treatment have significantly lower $S_{I}$ during the earlier 


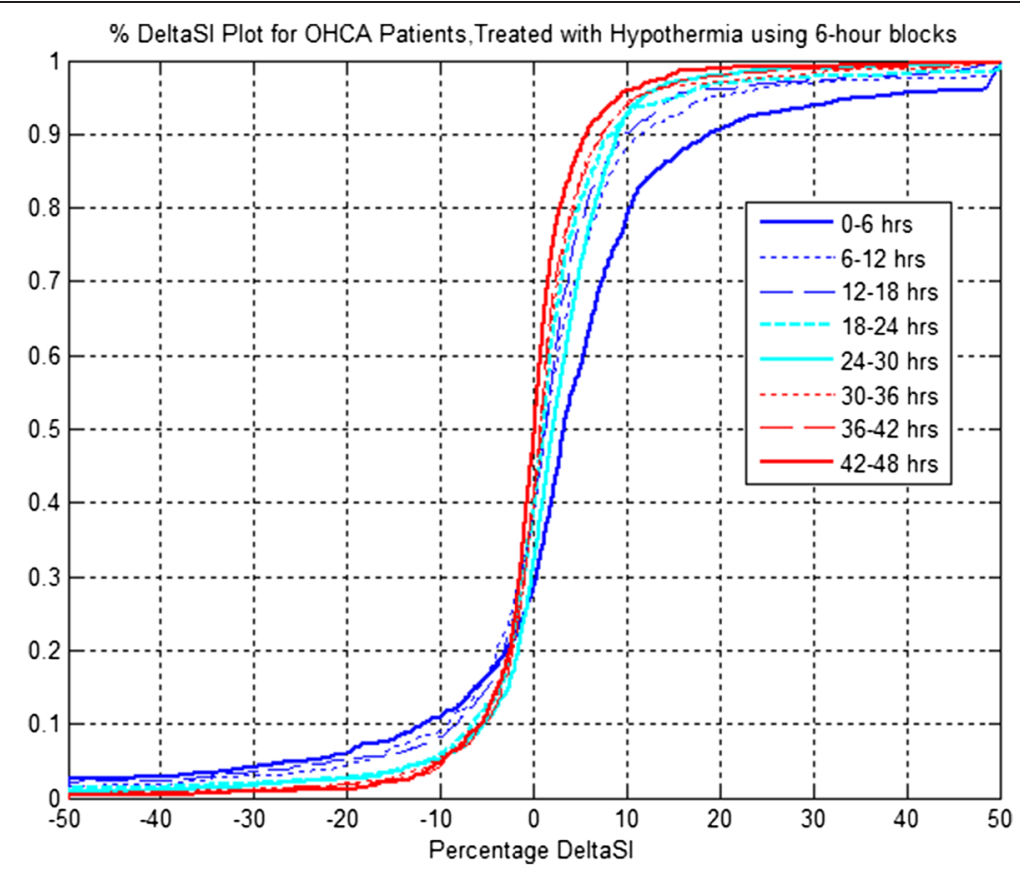

Figure 3 Insulin sensitivity variability distribution $\left(\% \Delta S_{1}\right)$ per cohort for out-of-hospital cardiac arrest $(\mathrm{OHCA})$ patients, treated with therapeutic hypothermia (TH) using six-hour blocks for both cool and warm periods.

cool period on day 1 than the later warm period on day 2. Both results determine the general trend for overall increasing $\mathrm{S}_{\mathrm{I}}$ level for critically ill patients over time and are consistent with other ICU studies [14,27]. Further analysis shows that the increase in $S_{I}$ level during the first 36 hours are large and statistically significant for this cohort. The rapid increases in $S_{I}$ level for the first 36 hours is likely due to significant restart of human physiological systems and metabolic activities for these patients [13]. After 36 hours, the rapid $S_{\mathrm{I}}$ increase abates as the patients' metabolism improves and becomes more stable.

\section{Insulin sensitivity variability}

Both per-cohort and per-patient analysis suggest that OHCA patients undergoing $\mathrm{TH}$ treatment have high initial variability that decreases over the first 36 hours.
However, the cool to warm transition at 24 hours shows an increase in variability likely due to the change of physiological conditions as body temperature increases from cool to warm between 18 and 36 hours. The lower decrease in $\mathrm{S}_{\mathrm{I}}$ variability after the 36th hour onward suggests that the patients' metabolic condition has improved and become more stable.

Further analysis and comparison of $\mathrm{S}_{\mathrm{I}}$ variability between general ICU patients [14] and OHCA patients treated with $\mathrm{TH}$ shows that the main difference between them is the $S_{I}$ variability increase during the cool to warm transition period for the latter cohort. These $S_{I}$ variability results do not follow the same trend with other general ICU studies by Pretty et al. [14], and it is a unique finding for this cohort that could significantly impact glycaemic control and safety from hypoglycaemia.

Table 4 Proportion of patients for whom median insulin sensitivity increases between the blocks indicated in the row and columns

\begin{tabular}{llllllll}
\hline & $\mathbf{6 - 1 2} \mathbf{~ h r}$ & $\mathbf{1 2 - 1 8} \mathbf{~ h r}$ & $\mathbf{1 8 - 2 4} \mathbf{~ h r}$ & $\mathbf{2 4 - 3 0} \mathbf{~ h r}$ & $\mathbf{3 0 - 3 6} \mathbf{~ h r}$ & $\mathbf{3 6 - 4 2} \mathbf{~ h r}$ & $\mathbf{4 2 - 4 8} \mathbf{~ h r}$ \\
\hline $0-6 \mathrm{hr}$ & 0.72 & 0.74 & 0.79 & 0.83 & 0.84 & 0.85 & 0.86 \\
$6-12 \mathrm{hr}$ & & 0.66 & 0.72 & 0.74 & 0.76 & 0.82 & 0.82 \\
$12-18 \mathrm{hr}$ & & & 0.69 & 0.70 & 0.75 & 0.79 & 0.70 \\
$18-24 \mathrm{hr}$ & & & 0.66 & 0.65 & 0.79 & 0.72 \\
$24-30 \mathrm{hr}$ & & & & & 0.58 & 0.68 \\
$30-36 \mathrm{hr}$ & & & & & & & 0.51 \\
$36-42 \mathrm{hr}$ & & & & & & & \\
\hline
\end{tabular}




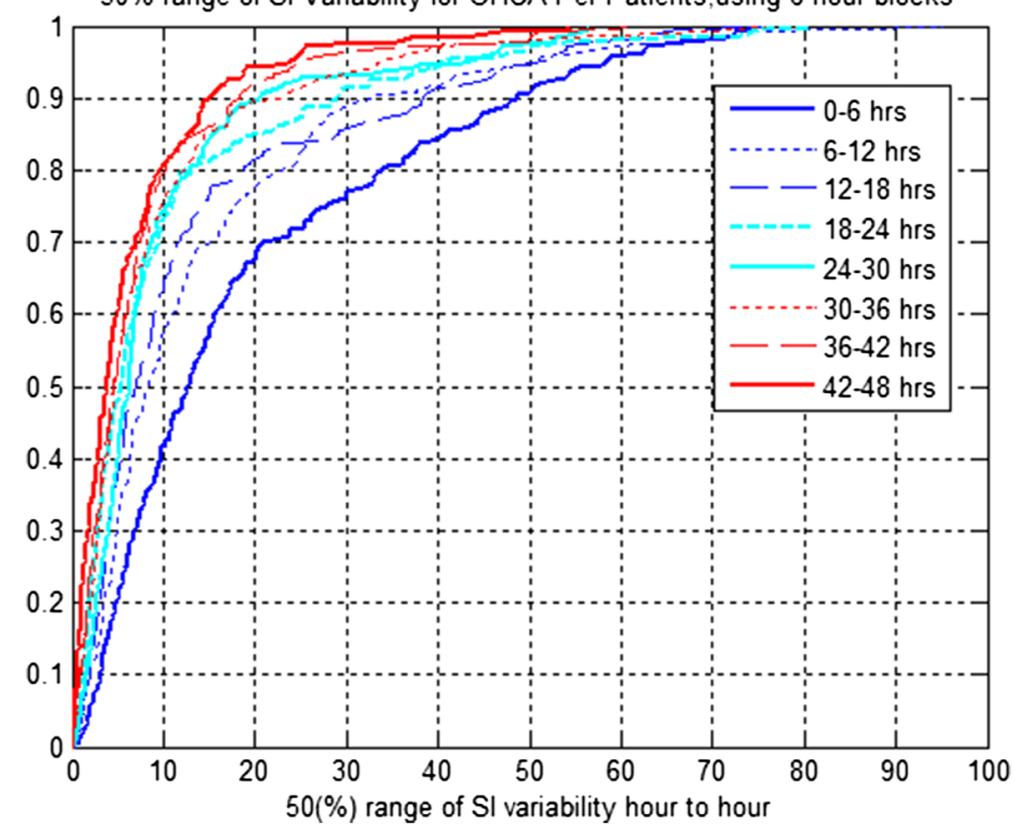

Figure 4 Per-patient $50 \%$ range of $\mathrm{S}_{1}$ variability distribution of out-of-hospital cardiac arrest (OHCA) patients, treated with therapeutic hypothermia (TH) using six-hour blocks for both cool and warm periods.

Table 5 Reductions in the interquartile range and median $S_{1}$ per patient range of hour-to-hour percentage $S_{\text {I }}$ change over time during cool and warm periods as per six-hour blocks of data, where the $P$ values compare successive six-hour blocks as shown in the first column for both the overall cohort and per-patient median values

\begin{tabular}{|c|c|c|c|c|}
\hline \multirow{2}{*}{$\begin{array}{l}\text { SI variability } \\
\text { analysis } \\
\text { [6-hr blocks] }\end{array}$} & \multicolumn{2}{|c|}{ Cohort analysis } & \multicolumn{2}{|c|}{ Per-patient analysis } \\
\hline & $\begin{array}{l}\text { \% reduction } \\
\text { of IQR }\end{array}$ & $P$ value & $\begin{array}{l}\% \text { median } \\
\text { decrease }\end{array}$ & $P$ value \\
\hline Block 1-2 (C) & 11.1 & $<0.05$ & 33.6 & $<0.05$ \\
\hline \multicolumn{5}{|l|}{ (0-6 vs. 6-12 hr) } \\
\hline Block 2-3 (C) & 20.7 & $<0.05$ & 15.8 & $<0.05$ \\
\hline \multicolumn{5}{|l|}{ (6-12 vs. $12-18 \mathrm{hr}$ ) } \\
\hline Block 3-4 (C) & 14.4 & $<0.05$ & 22.6 & $<0.05$ \\
\hline \multicolumn{5}{|l|}{ (12-18 vs. $18-24$ hr) } \\
\hline Block 4-5 (C-W) & -19.7 & $<0.05$ & -14.9 & $<0.05$ \\
\hline \multicolumn{5}{|l|}{ (18-24 vs. $24-30$ hr) } \\
\hline Block 5-6 (W) & 23.1 & $<0.05$ & 26.4 & 0.05 \\
\hline \multicolumn{5}{|l|}{ (24-30 vs. $30-36$ hr) } \\
\hline Block 6-7 (W) & 4.6 & $<0.05$ & 0.8 & 0.05 \\
\hline \multicolumn{5}{|l|}{ (30-36 vs. $36-42$ hr) } \\
\hline Block 7-8 (W) & 13.0 & 0.08 & 17.1 & 0.06 \\
\hline (36-42 vs. $42-48$ hr) & & & & \\
\hline
\end{tabular}

$P$ values are calculated using the Kolmogorov-Smirnov test. $S_{\mathrm{l}}$, insulin sensitivity metric (model-based); IQR, interquartile range.

\section{Implications for glycaemic control}

Clinically, these results have significant implications for managing glycaemia. Increased $S_{I}$ variability leads to increased variability in BG level for a given insulin intervention [11]. With low and variable insulin sensitivity, glycaemic levels might appear to remain unchanged and difficult to control effectively with exogenous insulin. This situation may result in increased glycaemic variability as well as an increased risk of hyperglycaemia and hypoglycaemia during the first 36 hours of treatment due to greater hour-to-hour $S_{\text {I }}$ variability with increased insulin resistance [17]. Thus, since glycaemic variability and hypoglycaemia are independent risk factors for the critically ill, it is important to understand and manage these patient-specific dynamics, especially those unique to a cohort, when implementing glycaemic control. This outcome is particularly important when OHCA patients transition from cool to warm. These results may also generalise to other areas where glycaemic control is applied to hypothermic patients, such as in the operating theatre.

There are several ways that this low and variable insulin sensitivity could be managed during glycaemic control. Reducing exogenous insulin doses, coupled with modulation of the glucose content of nutrition would diminish the impact of sudden changes of insulin sensitivity on glycaemic outcome. Equally, increased BG measurement frequency could improve control and reduce glycaemic variability. Accepting higher glycaemic targets during periods of 
increased variability would trade off a reduced risk of hypoglycaemia against increased hyperglycaemia. Ultimately, the preferred method for any unit may be influenced by practical considerations, such as clinical workload.

\section{Limitations}

The parameters used in the glucose insulin system model are based on general ICU patients with normal body temperature conditions. Thus, the insulin sensitivity values derived during the cool period could be biased by modelling errors or unmodelled effects. However, as noted previously, the validity and independence of this patient-specific parameter has been validated using data from clinically matched cohorts and has been shown to correlate well in gold-standard insulin sensitivity tests.

Insulin sensitivity variability is a key contributor to glycaemic variability. Sechterberger et al. [28] showed an association between high glycaemic variability and mortality is not present in diabetic cohorts. Thus, a subgroup analysis of diabetic OHCA patients in this study would be very interesting. However, only 26 of 200 (13\%) OHCA patients in this study had previously diagnosed diabetes (Table 1), which is too few to enable a reliable analysis with these methods. Additionally, in this particular cohort, undiagnosed diabetes or impaired glucose regulation [29] may confound such a subgroup.

\section{Conclusions}

This study analyses the metabolic evolution of OHCA patients treated with $\mathrm{TH}$. These analyses characterise the metabolic impact of $\mathrm{TH}$ treatment on the level and variability of insulin sensitivity to inform control.

Two main conclusions are drawn as a result for these cohorts.

i) $\mathrm{S}_{\mathrm{I}}$ level is much lower during $\mathrm{TH}$ and consistently increases over time, during both cool and warm periods.

ii) Insulin sensitivity is more variable during the cool period and shows contrasting behaviour during the cool to warm transition period between 18 and 30 hours, which indicates that there are major changes in physiology and metabolic conditions between cool and warm as influenced by human body temperature. Otherwise, it decreases over time.

Finally, this study shows the need for patient-specific glycaemic management to ensure good control and safety during treatment. These results have significant potential clinical impact on the metabolic treatment of these patients, and changes in clinical therapy are required to safely treat patients as they transition from cool to warm.

\section{Key messages}

- OCHA patients treated with TH have significantly lower and highly variable $S_{I}$ during the first 24 hours of the cool period, compared to the later warm period in their ICU stay.

- There is an overall trend of increasing $S_{I}$ over the first 36 hours, both per-cohort and per-patient results.

- $S_{I}$ variability decreases consistently over time, except for a large, statistically significant increase during the cool to warm transition at 24 hours.

- This increase requires special consideration for glycaemic control as it increases risk of hypoglycaemia, BG variability and thus mortality.

\section{Abbreviations}

$\% \Delta$ SI: hour-to-hour percentage changes in insulin sensitivity; BG: blood glucose; CDF: cumulative distribution function; ICU: intensive care unit; IQR: interquartile range; KS: Kolmogorov-Smirnov (test); OHCA: out-of-hospital cardiac arrest; $S_{\text {: }}$ insulin sensitivity metric (model-based); SPRINT: specialized relative insulin and nutrition titration; $\mathrm{TH}$ : therapeutic hypothermia.

\section{Competing interests}

The authors declare that they have no competing interests.

\section{Authors' contributions}

ASP processed raw patient data from conventional spreadsheet into Matlab format, prepared statistical analysis and summarized results for interpretation. ASP, JGC, CGP, SP, and TD drafted the manuscript, performed analysis and interpretation of the data and critical revision of the manuscript for

important intellectual content. GS provided clinical insight and supervised the acquisition of clinical data from Christchurch ICU patients. JCP, FT, JLV and $\mathrm{MO}$ provided clinical insight and supervised the acquisition of clinical data from Erasme and Lausanne ICU patients. All authors read and approved the final draft of the manuscript.

\section{Author details}

${ }^{1}$ Centre for Bio-Engineering, Department of Mechanical Engineering, University of Canterbury, 20 Kirkwood Avenue, Christchurch 8140, New Zealand. ${ }^{2}$ Department of Intensive Care, Christchurch Hospital, Riccarton Avenue, Christchurch 8140, New Zealand. ${ }^{3}$ Department of Intensive Care, Erasme University Hospital (CUB), University of Brussels, Route de Lennik 808, 1070 Brussels, Belgium. ${ }^{4}$ Department of Intensive Care, Lausanne University Hospital (CHUV), Rue du Bugnon 46, 1011 Lausanne, Switzerland. ${ }^{5}$ Cardiovascular Research Center, Universite de Liege, Allée du 6 Août 17, B4000 Liege, Belgium.

Received: 25 May 2014 Accepted: 10 October 2014

Published online: 28 October 2014

\section{References}

1. Capes SE, Hunt D, Malmberg K, Gerstein HC: Stress hyperglycaemia and increased risk of death after myocardial infarction in patients with and without diabetes: a systematic overview. Lancet 2000, 355:773-778.

2. McCowen KC, Malhotra A, Bistrian BR: Stress-induced hyperglycemia. Crit Care Clin 2001, 17:107-124.

3. Mizock BA: Alterations in fuel metabolism in critical illness: hyperglycaemia. Best Pract Res Clin Endocrinol Metab 2001, 15:533-551.

4. van den Berghe G, Wouters P, Weekers F, Verwaest C, Bruyninckx F, Schetz M, Vlasselaers D, Ferdinande $P$, Lauwers $P$, Bouillon R: Intensive insulin therapy in critically ill patients. N Engl J Med 2001, 345:1359-1367.

5. Krinsley JS: Association between hyperglycemia and increased hospital mortality in a heterogeneous population of critically ill patients. Mayo Clin Proc 2003, 78:1471-1478.

6. Krinsley JS: Effect of an intensive glucose management protocol on the mortality of critically ill adult patients. Mayo Clin Proc 2004, 79:992-1000. 
7. Chase JG, Shaw G, Le Compte A, Lonergan T, Willacy M, Wong XW, Lin J, Lotz T, Lee D, Hann C: Implementation and evaluation of the SPRINT protocol for tight glycaemic control in critically ill patients: a clinical practice change. Crit Care 2008, 12:R49.

8. Brunkhorst FM, Engel C, Bloos F, Meier-Hellmann A, Ragaller M, Weiler N, Moerer O, Gruendling M, Oppert M, Grond S, Olthoff D, Jaschinski U, John S, Rossaint R, Welte T, Schaefer M, Kern P, Kuhnt E, Kiehntopf M, Hartog C, Natanson C, Loeffler M, Reinhart K, S German Competence Network: Intensive insulin therapy and pentastarch resuscitation in severe sepsis. N Engl J Med 2008, 358:125-139.

9. Finfer S, Chittock DR, Su SY, Blair D, Foster D, Dhingra V, Bellomo R, Cook D, Dodek P, Henderson WR, Hebert PC, Heritier S, Heyland DK, McArthur C, McDonald E, Mitchell I, Myburgh JA, Norton R, Potter R, Robinson BG, Ronco $\mathrm{JJ}$ : Intensive versus conventional glucose control in critically ill patients. N Engl J Med 2009, 360:1283-1297.

10. Preiser JC, Devos P, Ruiz-Santana S, Melot C, Annane D, Groeneveld J, lapichino G, Leverve X, Nitenberg G, Singer P, Wernerman J, Joannidis M, Stecher A, Chiolero R: A prospective randomised multi-centre controlled trial on tight glucose control by intensive insulin therapy in adult intensive care units: the Glucontrol study. Intensive Care Med 2009, 35:1738-1748.

11. Chase JG, Le Compte AJ, Suhaimi F, Shaw GM, Lynn A, Lin J, Pretty CG, Razak N, Parente JD, Hann CE, Preiser JC, Desaive T: Tight glycemic control in critical care-the leading role of insulin sensitivity and patient variability: a review and model-based analysis. Comput Methods Programs Biomed 2011, 102:156-171.

12. Taylor NA, Griffiths RF, Cotter JD: Epidemiology of hypothermia: fatalities and hospitalisations in New Zealand. Aust N Z J Med 1994, 24:705-710.

13. Neumar RW, Nolan JP, Adrie C, Aibiki M, Berg RA, Bottiger BW, Callaway C, Clark RS, Geocadin RG, Jauch EC, Kern KB, Laurent I, Longstreth WT, Merchant MR Jr, Morley P, Morrison $\sqcup$, Nadkarni V, Peberdy MA, Rivers EP, Rodriguez-Nunez A Sellke FW, Spaulding C, Sunde K, Vanden Hoek T: Post-cardiac arrest syndrome: epidemiology, pathophysiology, treatment, and prognostication. A consensus statement from the International Liaison Committee on Resuscitation (American Heart Association, Australian and New Zealand Council on Resuscitation, European Resuscitation Council, Heart and Stroke Foundation of Canada, InterAmerican Heart Foundation, Resuscitation Council of Asia, and the Resuscitation Council of Southern Africa); the American Heart Association Emergency Cardiovascular Care Committee; the Council on Cardiovascular Surgery and Anesthesia; the Council on Cardiopulmonary, Perioperative, and Critical Care; the Council on Clinical Cardiology; and the Stroke Council. Circulation 2008, 118:2452-2483.

14. Pretty CG, Le Compte AJ, Chase JG, Shaw GM, Preiser JC, Penning S, Desaive T: Variability of insulin sensitivity during the first 4 days of critical illness: implications for tight glycemic control. Ann Intensive Care 2012, 2:17.

15. Eisenburger P, Sterz F, Holzer M, Zeiner A, Scheinecker W, Havel C, Losert H: Therapeutic hypothermia after cardiac arrest. Curr Opin Crit Care 2001, 7:184-188.

16. Lee $\mathrm{R}$, Asare K: Therapeutic hypothermia for out-of-hospital cardiac arrest. Am J Health Syst Pharm 2010, 67:1229-1237.

17. Cueni-Villoz N, Devigili A, Delodder F, Cianferoni S, Feihl F, Rossetti AO, Eggimann P, Vincent JL, Taccone FS, Oddo M: Increased blood glucose variability during therapeutic hypothermia and outcome after cardiac arrest. Crit Care Med 2011, 39:2225-2231.

18. Hayashi N: Management of pitfalls for the successful clinical use of hypothermia treatment. J Neurotrauma 2009, 26:445-453.

19. Chase JG, Suhaimi F, Penning S, Preiser JC, Le Compte AJ, Lin J, Pretty CG, Shaw GM, Moorhead KT, Desaive T: Validation of a model-based virtual trials method for tight glycemic control in intensive care. Biomed Eng Online 2010, 9:84.

20. Evans A, Shaw GM, Le Compte A, Tan CS, Ward L, Steel J, Pretty CG, Pfeifer L, Penning S, Suhaimi F, Signal M, Desaive T, Chase JG: Pilot proof of concept clinical trials of Stochastic Targeted (STAR) glycemic control. Ann Intensive Care 2011, 1:38

21. Lin J, Razak NN, Pretty CG, Le Compte A, Docherty P, Parente JD, Shaw GM, Hann CE, Geoffrey Chase J: A physiological Intensive Control InsulinNutrition-Glucose (ICING) model validated in critically ill patients. Comput Methods Programs Biomed 2011, 102:192-205.

22. McAuley KA, Berkeley JE, Docherty PD, Lotz TF, Te Morenga LA, Shaw GM, Williams SM, Chase JG, Mann J: The dynamic insulin sensitivity and secretion test-a novel measure of insulin sensitivity. Metabolism 2011, 60:1748-1756.

23. Fisk LM, Le Compte AJ, Shaw GM, Penning S, Desaive T, Chase JG: STAR development and protocol comparison. IEEE Trans Biomed Eng 2012, 59:3357-3364.

24. Pretty CG, Signal M, Fisk L, Penning S, Le Compte A, Shaw GM, Desaive T, Chase JG: Impact of sensor and measurement timing errors on model-based insulin sensitivity. Comput Methods Programs Biomed 2014 114:e79-e86.

25. Hann CE, Chase JG, Lin J, Lotz T, Doran CV, Shaw GM: Integral-based parameter identification for long-term dynamic verification of a glucoseinsulin system model. Comput Methods Programs Biomed 2005, 77:259-270.

26. Bagshaw SM, Egi M, George C, Bellomo R, Australia New Zealand Intensive Care Society Database Management C: Early blood glucose control and mortality in critically ill patients in Australia. Crit Care Med 2009, 37:463-470.

27. Langouche L, Vander Perre S, Wouters PJ, D'Hoore A, Hansen TK, Van den Berghe G: Effect of intensive insulin therapy on insulin sensitivity in the critically ill. J Clin Endocrinol Metab 2007, 92:3890-3897.

28. Sechterberger MK, Bosman RJ, Oudemans-van Straaten HM, Siegelaar SE, Hermanides J, Hoekstra JB, De Vries JH: The effect of diabetes mellitus on the association between measures of glycaemic control and ICU mortality: a retrospective cohort study. Crit Care 2013, 17:R52.

29. Bartnik M, Ryden L, Ferrari R, Malmberg K, Pyorala K, Simoons M, Standl E, Soler-Soler J, Ohrvik J, Euro Heart Survey I: The prevalence of abnormal glucose regulation in patients with coronary artery disease across Europe. The Euro Heart Survey on diabetes and the heart. Eur Heart $J$ 2004, 25:1880-1890.

\section{doi:10.1186/s13054-014-0586-x}

Cite this article as: Sah Pri et al:: Evolution of insulin sensitivity and its variability in out-of-hospital cardiac arrest (OHCA) patients treated with hypothermia. Critical Care 2014 18:586.

\section{Submit your next manuscript to BioMed Central and take full advantage of:}

- Convenient online submission

- Thorough peer review

- No space constraints or color figure charges

- Immediate publication on acceptance

- Inclusion in PubMed, CAS, Scopus and Google Scholar

- Research which is freely available for redistribution 